\title{
Treatment Acceptability among Crime Victims
}

\author{
O. Semb $b^{1, *}$, P. Fransson ${ }^{2}$, M. Henningsson ${ }^{2}$ and E. Sundbom ${ }^{1}$ \\ ${ }^{1}$ Department of Clinical Sciences, Division Psychiatry and Medical Psychology, Umeå University, Sweden \\ ${ }^{2}$ Department of Psychology, Umeå University, Sweden
}

\begin{abstract}
Crime victims receive relevant treatment too seldom and there is uncertainty as to whether those who need the treatment the most are among those who get it. Fifty-two consecutive adult crime victims were offered 10 sessions of psychotherapy within two weeks after an experienced trauma of criminal victimization. Twenty-six accepted and 26 declined the offer. The aim of the study was to explore some of the differences between these two groups. The results show that the therapy group presented a higher incidence of acute stress disorder, more negative scorings regarding immediate reactions (to the crime), more subjective ratings of physical and psychological health (GAF, according to DSM IV), and more psychiatric and trauma-related symptoms as compared to the non-therapy group. A conclusion was that those who needed treatment the most also accepted it. Traumatized people may, due to avoidant strategies, withdraw from potential treatment. Conversely, the therapy group scored higher on the coping style escape-avoidance.
\end{abstract}

Keywords: Crime victims, psychiatric symptoms, psychotherapy, coping, treatment acceptability.

\section{INTRODUCTION}

Being exposed to a violent crime is often a sudden, shocking, and negative experience. The events may affect many realms of human life, including the psychological, social, physical, moral, and economical. Exposure to violent crime is a risk factor for developing severe trauma symptoms and general mental health problems. For example, it has been shown that half of the victims of street robbery can be classified as "psychiatric cases" within 3 weeks after the crime [1]. The same study showed that women present more psychological distress than men.

As post traumatic stress disorder (PTSD) [2] is a prominent diagnosis in the research literature when using the key word "crime victim," some short remarks about PTSD will follow, even if PTSD is not the focus of this study per se. PTSD is an extreme stress reaction that may follow exposure to severe traumas. There are three clusters of main symptoms: intrusion, avoidance, and arousal. These symptoms have a massive impact on the afflicted person's life. Acute stress disorder (ASD) [2] is a diagnosis with criteria similar to PTSD. The main difference is that ASD can be applied before one month after the traumatic event. In the case of more persistent symptoms, a PTSD diagnosis may be relevant if the criteria are fulfilled. Kilpatrick and Acierno [3] expressed prevalences of PTSD of between 23 and $39 \%$ among victims of physical assault. Another study [4] showed that $24 \%$ of the crime-victimized patients visiting a Danish emergency ward filled the criteria for ASD, while a further $21 \%$ suffered from sub-clinical ASD. There is a strong connection between ASD and PTSD; several studies have shown

*Address correspondence to this author at the Department of Clinical Sciences, Division of Psychiatry, Umeå University Hospital, 90187 Umeå, Sweden; Tel: 0046738471307; Fax: +46907856493;

E-mail: olof.semb@psychiat.umu.se that about $75 \%$ of trauma survivors diagnosed with ASD are later diagnosed with PTSD $[5,6]$.

The importance of assessing crime victims' reactions and symptoms has been emphasized for a number of reasons, for example to offer information about guidelines for psychotherapeutic interventions. Depending on the context, i.e., research, clinical or forensic work, different combinations of quantitative and qualitative assessment tools are recommended [7]. It has been argued that early assessment is important in identifying victims who are at risk for developing PTSD or other severe psychopathology $[5,8]$. There are a number of predictive factors for those who are at risk for developing post traumatic disorders. Ehring, Ehlers, and Gluckman, [9] have recently shown that cognitive factors also have predictive power.

Psychological debriefing is an intuitively appropriate intervention for traumatized people, but the methods involved have been called into serious question by a number of researchers, e.g. Kamphuis and Emmelkamp, and Litz et al. $[10,11]$. The situation is more optimistic regarding psychotherapeutic interventions. Promising results have been reported by Grant, and Resick et al. [12, 13], among others, but the main impression is that we still do not know enough [14]. Clinicians treating traumatized people often encounter various obstacles from their patients, such as excessive avoidance, extreme anxiety, substance abuse, ongoing stressors, and poor motivation. These obstacles tend to interfere with treatment and lead to high dropout rates [15].

Only a minority of adult crime victims seek treatment. In one study, only $12 \%$ of this group had received help from mental health professionals within three months after the crime [16]. Crime victims are at risk for developing PTSD and/or other psychological disorders [7]. A likely conclusion is that many crime victims do not receive the treatment they need, which makes it important to investigate help-seeking 
patterns and treatment acceptability among crime victims. The latter refers to the expectations of potential consumers of treatment that the treatment will be fair, justified, reasonable, and agreeable [17]. The information on this issue, however, is rather scant and ambiguous. In one study, Carlson \& Dutton asked whether the adult crime victims who are most in need of help are also those who experience the most difficulties in complying with the treatment [7]. This can be seen in view of the fact that avoidant strategies appear to be a hallmark of long-lasting suffering among traumatized people $[18,19]$. On the other hand, the main impression left on Clarkin \& Levy, who reviewed a number of studies describing the characteristics of those who seek therapy and those who do not, was that those who seek treatment have more symptoms, more emotional distress, and more ongoing life stress, among other things [20]. Hembree and Foa showed that PTSD diagnoses in crime victims appear to be associated with a need for mental health services [21]. Naturally, crime victims are a heterogeneous group of people, which is a further factor that makes it important to compare those who attend psychotherapy and those who do not.

Coping is probably one of the most investigated concepts in behavioral science. For example, there are numerous studies of the relationships between coping strategies and health. The coping strategies of accepting responsibility and of avoidance, among others, have been shown to be associated with negative overall health outcomes [22]. Social support may be a shield against traumatic events; in one study on crime victims, there was an inverse relationship between social support and avoidance-oriented coping [23]. Coping can therefore be assumed to be involved in the acceptance of therapy participation.

\section{AIMS}

The aim of this study was to explore the differences between crime victims who accepted and declined, respectively, an offer of psychotherapeutic treatment. Dependent variables were frequencies of ASD, immediate reactions (to the crime), subjective ratings of physical and psychological health, GAF (according to DSM IV), psychiatric symptoms, traumatic symptoms, and coping strategies.

\section{METHOD}

\section{Participants}

This study is part of a two-year longitudinal study on 91 crime victims who did or did not undergo psychotherapeutic interventions. Fifty-two consecutive adult crime victims (31 men and 21 women) were contacted directly after the crime. The age ranged from 18 to 64 ; mean (SD) age 33 (12.72); men, mean age 34 (12.50) and women, mean age 31 (13.04). Inclusion criteria were experience or threat of severe interpersonal violence. Exclusion criteria were traumatic brain injury, known criminality, psychotic disorders, intimate partner violence, and severe substance abuse. There were some missing data regarding the questionnaires used in this study, which will be accessible in the results. The rationale behind the exclusion criteria is that one of the aims of the project is to explore reactions after a single-event of victimization were the perpetrator was previously unknown by the victim. The project was approved by the Regional victim. The project was approved by the Regional Ethical Review Board in Umeå (D.no. 03-408 and 05-035M). The study was supported from the Crime Victims' Support and Compensation Authority and Umeå University. Informed consent was obtained at first admission and a contract was signed by all participants.

\section{Procedure}

Shortly after the crime, the victims were informed about the project by a police officer assigned to providing information and service to crime victims. Those who were positive to joining the project were contacted by a member of the project team and an appointment for a first meeting was arranged. During this appointment, a clinical audio taped interview was performed and questionnaires were filled out, after which the participants were offered a trial of psychotherapy (see below). The psychotherapies were carried out by registered clinical psychologists during a maximum of 10 sessions. In total, 26 subjects accepted and 26 rejected the psychotherapeutic offer. The most common reason for declining was that they said they felt fine and did not need therapy. Other reasons were of a practical nature or skepticism to the value of psychotherapy. The offer and the information given to the victims was that they would, together with a therapist, make a clarification of the problems, encouraging the victim to express their emotions around the trauma and to reduce the distress by getting support and help to restore the basic trust by psycho-educative and counseling elements. Also they would be aided in seeking alternative problem-solving strategies in order to to handle the actual critical life situation.

\section{Measures}

A semi-structured clinical interview consisting of 27 questions, including both quantitative and qualitative measures, was constructed. It consisted of two parts, with the first part aimed at capturing present experiences and reactions. This included narratives about the crime, examination of the criteria for acute stress disorder (ASD) according to DSM-IV [2] where the participants were asked to indicate presence or absence of trauma-specific symptoms, event-related emotions, demographic data, social network, and leisure-time activities. The second part focused on past experiences, including family life, school. Three questions in this part focused on physical and psychological health at the time just before the crime, just after the crime, and in the future. This was measured by the subjects themselves on a visual analog scale (VAS) ranging from 1 (lowest possible) to 10 (best possible). Finally, a global assessment of functioning (GAF) scale according to DSM-IV was scored on the basis of the entire clinical interview. To measure "fear," "loss of control," "immediate reactions," and negative "impact on life during the first week" after the crime, the investigators listened to the audio tapes and scored the subjects' narratives on a three-grade Likert scale ( $1=$ none/low, $2=$ moderate, and $3=$ high). The interrater reliability estimates for a sample of 10 participants with four independent judges was tested. ETA $\left(\eta^{2}\right)$ was calculated using SPSS crosstabs and three separate computations of explained variance were obtained. The three $\eta^{2}$ were: Fear $=0.152$, Helplessness $=0.214$, and 
Negative emotional reaction $=0.194$. This means that $84.8 \%$ of the variance in Fear during the crime was independent of individual judges, and the percentages of judge-independent variance in the other variables were 78.6 and 80.6 , respectively.

The Harvard Trauma Questionnaire (HTQ) (Mollica et al., 1992) is a 30-item questionnaire of which 16 PTSD items correspond to the three core symptoms in PTSD (avoidance, intrusion, and arousal) in the DSM-IV and 14 of them are general trauma items on a four-graded Likert scale (1="not at all," 2="some," 3="a lot," and 4="extreme"). Respondents are instructed to report trauma symptoms over the last seven days. The psychometrics in the original article by Mollica et al. [24] showed good internal consistency, testretest validity, and concurrent validity. The alpha value for the current study was good $(\alpha=.92)$. Alpha values on the three subscales were acceptable as well; Intrusion $=.82$; Avoidance $=.86 ;$ Arousal $=.86$.

The Symptom Checklist-90 (SCL-90) is a 90-item questionnaire measuring current general psychiatric health in 10 primary dimensions: Somatization, Obsessive-Compulsive, Interpersonal Sensitivity, Depression, Anxiety, Aggression (Hostility), Phobic Anxiety, Paranoid Ideation, and Psychoticism. It also has a scale measuring more wide-ranging symptoms not specifically related to any other dimension, like disordered sleep and suicidal ideation. The scale also contains three global subscales: Global Severity Index (average regardless of subscale), Positive Symptom Disorder Index (average of all non-0 answers), and Positive Symptoms Total (frequency of non-0 answers). Respondents are instructed to rate each item over the last seven days on a fivepoint scale ( $0=$ "not at all" to $5=$ "extreme"). A Swedish standardization exists with satisfying psychometric properties [25].

All symptom parameters were used as continuous scales so no cut-offs were used in this study.
The Ways of Coping Questionnaire (WCQ) is a selfreport questionnaire aimed at measuring coping strategies [26]. The test consists of eight clusters: Confrontative Coping, Distancing, Self-Controlling, Seeking Social Support, Accepting Responsibility, Escape-avoidance, Planful Problem Solving, and Positive Reappraisal. The test consists of 66 items and the subjects are asked to rate their coping reactions, in relation to a stressful event, on a four-graded scale $(0=$ "does not apply/not used" to $3=$ "used a great deal"). Acceptable internal consistency estimates for the eight clusters have been shown for the English version [27] and for the total score in a Swedish translation [28].

\section{Statistical Methods}

Descriptive statistics, non-parametric $\mathrm{Chi}^{2}$, and independent Student's T-test were computed using SPSS 15.

\section{RESULTS}

In calculating the result, the therapy and non-therapy group were compared to each other in the following order: frequencies of ASD (presented in Table 1), immediate reactions (Table 2), subjective ratings of physical and psychological health (VAS) and GAF (Table 3), and psychiatric symptoms and coping strategies (Tables 4 and 5). Due to missing data, there are different numbers of $n$ with regard to the different questionnaires used in this study.

Table 1 shows that half of the subjects accepted therapy and that the therapy group included more individuals assessed as ASD than the non-therapy group. The group difference was significant $\left(\mathrm{Chi}^{2}=22.24, \mathrm{p}=.00\right)$.

The distribution of gender in the therapy and non-therapy group was uneven, with more women in the treatment group. The difference, however, was not significant $\left(\mathrm{Chi}^{2}=2.84\right.$, $\mathrm{p}=.08)$.

Table 1. Frequencies of Acute Stress Disorder (ASD) in the Therapy vs. the Non-Therapy Group (n=52)

\begin{tabular}{|l|c|c|c|}
\hline Group & Frequencies no ASD & Frequencies ASD & Total \\
\hline \hline Non-therapy group & 22 & 4 & 26 \\
\hline Therapy group & 5 & 21 & 26 \\
\hline
\end{tabular}

Table 2. Means and Standard Deviations for the Therapy vs. the Non-Therapy Group Regarding the Fear, Loss of Control and Immediate Reactions to the Crime $(\mathbf{n}=52)$

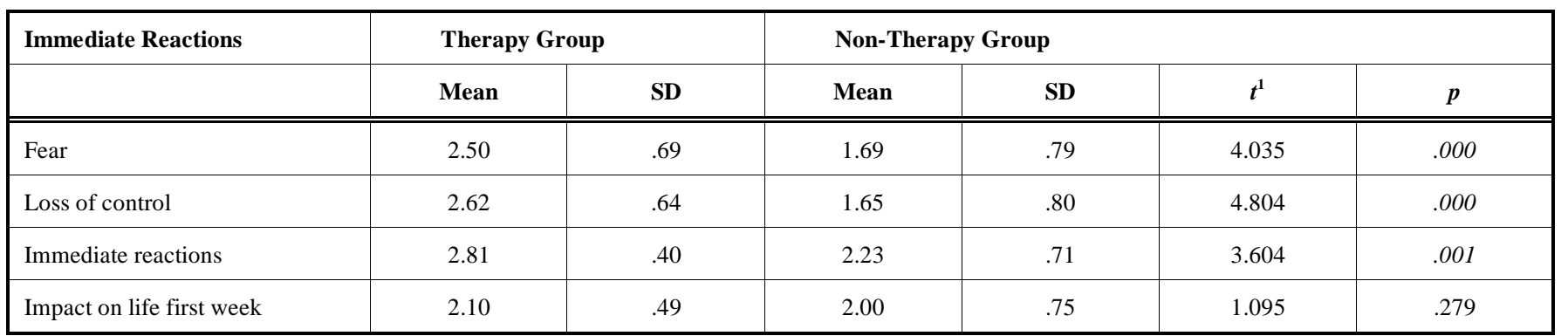

${ }^{1}$ Independent samples t-test for differences between therapy and non-therapy group. 
Table 2 shows that the therapy group reacted with more fear, more loss of control, and more severe immediate reactions than the non-therapy group.

Table 3 shows that the therapy group scored lower on the variable "Psychological Health" directly after the crime than the non-therapy group. They also received lower scores on the clinical GAF judgment. These differences were significant.
Table 4 shows that the therapy group higher symptom levels than the non-therapy group according to SCL-90 and HTQ.

Table 5 shows that there were few significant group differences in coping except that the therapy group scored higher on the coping strategies "Accepting Responsibility" and "Escape-Avoidance" than the non-therapy group.

Table 3. Means and Standard Deviations for the Therapy vs. the Non-Therapy Group Regarding Self-Rated Physical and Psychological Health on a 10-Grade VAS Scale Where 1 is Very Poor and 10 is Very Good. The Interviewers' GAF Ratings are Also Shown $(\mathbf{n}=52)$

\begin{tabular}{|c|c|c|c|c|c|c|}
\hline \multirow[t]{2}{*}{ Health Measures } & \multicolumn{2}{|c|}{ Therapy Group } & \multicolumn{4}{|c|}{ Non-Therapy Group } \\
\hline & Mean & SD & Mean & SD & $t^{1}$ & $p$ \\
\hline Physical health before crime, VAS & 7.77 & 1.61 & 8.00 & 1.96 & -.464 & .644 \\
\hline Physical health directly after crime, VAS & 5.12 & 2.16 & 6.27 & 2.78 & -1.666 & .102 \\
\hline Psychological health before crime, VAS & 7.38 & 2.10 & 8.04 & 1.49 & -1.297 & .200 \\
\hline Psychological health directly after crime, VAS & 4.12 & 1.86 & 6.65 & 2.20 & -4.503 & .000 \\
\hline Psychological health in future & 7.95 & 1.43 & 8.71 & 1.12 & -1.984 & .054 \\
\hline GAF & 57.00 & 8.25 & 73.15 & 11.20 & -5.920 & .000 \\
\hline
\end{tabular}

${ }^{1}$ Independent samples t-test for differences between therapy and non-therapy group.

Table 4. Means and Standard Deviations for the Therapy and Non-Therapy Group for SCL-90 and HTQ (n=41)

\begin{tabular}{|c|c|c|c|c|c|c|}
\hline \multirow[t]{2}{*}{ Symptoms } & \multicolumn{2}{|c|}{ Therapy Group } & \multicolumn{4}{|c|}{ Non-Therapy Group } \\
\hline & Mean & SD & Mean & SD & $t^{1}$ & $p$ \\
\hline Somatization, SCL-90 & 1.07 & .64 & 0.60 & .76 & 2.147 & .038 \\
\hline Obsessive-compulsive, SCL-90 & 1.60 & .81 & 0.68 & .59 & 4.049 & .000 \\
\hline Interpersonal sensitivity, SCL-90 & 1.20 & .77 & 0.54 & .69 & 2.850 & .007 \\
\hline Depression, SCL-90 & 1.51 & .98 & 0.68 & .55 & 3.405 & .002 \\
\hline Anxiety, SCL-90 & 1.47 & .85 & 0.49 & .76 & 3.774 & .001 \\
\hline Aggression (Hostility), SCL-90 & 0.92 & .78 & 0.45 & .66 & 2.093 & .048 \\
\hline Phobic anxiety, SCL-90 & 1.13 & .92 & 0.61 & 1.05 & 1.693 & .098 \\
\hline Paranoid ideation, SCL-90 & 1.07 & .85 & 0.51 & .72 & 2.281 & .028 \\
\hline Psychoticism, SCL-90 & 0.46 & .64 & 0.26 & .37 & 1.172 & .248 \\
\hline Additional scale, SCL-90 & 1.40 & .99 & 0.56 & .61 & 3.309 & .002 \\
\hline Global severity index, SCL-90 & 1.16 & .62 & 0.53 & .60 & 3.187 & .003 \\
\hline HTQ Total & 2.01 & 0.50 & 1.50 & 0.56 & 3.030 & .004 \\
\hline Intrusion, HTQ & 2.19 & 0.61 & 1.67 & 0.82 & 2.353 & .024 \\
\hline Avoidance, HTQ & 2.01 & 0.65 & 1.56 & 0.61 & 2.271 & .029 \\
\hline Arousal, HTQ & 2.45 & 0.70 & 1.69 & 0.83 & 3.221 & .003 \\
\hline
\end{tabular}

${ }^{1}$ Independent samples t-test for differences between therapy and non-therapy group. 
Table 5. Means and Standard Deviations for the Therapy and Non-Therapy Group Regarding Coping Strategies in WCQ (n=33)

\begin{tabular}{|c|c|c|c|c|c|c|}
\hline \multirow[t]{2}{*}{ Coping Strategies } & \multicolumn{2}{|c|}{ Therapy Group } & \multicolumn{4}{|c|}{ Non-Therapy Group } \\
\hline & Mean & SD & Mean & SD & $t^{1}$ & $p$ \\
\hline Confrontative & 0.82 & 0.47 & 0.92 & 0.71 & -.478 & .636 \\
\hline Distancing & 0.87 & 0.41 & 0.81 & 0.51 & .374 & .711 \\
\hline Self-controlling & 1.18 & 0.43 & 1.02 & 0.47 & 1.040 & .307 \\
\hline Seeking social support & 1.62 & 0.89 & 1.38 & 0.81 & .811 & .423 \\
\hline Accepting responsibility & 1.17 & 0.85 & 0.43 & 0.62 & 2.787 & .005 \\
\hline Escape-avoidance & 1.08 & 0.51 & 0.60 & 0.54 & 2.625 & .013 \\
\hline Planful problem solving & 1.06 & 0.51 & 1.13 & 0.66 & -.357 & .724 \\
\hline Positive reappraisal & 0.72 & 0.39 & 0.70 & 0.52 & .109 & .914 \\
\hline
\end{tabular}

${ }^{1}$ Independent samples t-test for differences between therapy and non-therapy group.

\section{DISCUSSION}

The main results showed that the therapy group scored higher, compared to the non-therapy group, regarding the incidence of acute stress disorder. They also showed more negative scorings regarding immediate reactions (to the crime), subjective ratings of physical and psychological health, GAF (according to DSM IV), psychiatric symptoms, and trauma-related symptoms. In the clinical interview, it was also obvious that the non-treatment group felt much better than the treatment group. When asked why they did not accepted the offer of treatment, they often answered, "It's not necessary, I feel fine," or "Other people need it better than I do." Hence, the results suggest that the crime victims who declined therapy were psychologically better off than those who took part in the therapeutic intervention. This result is similar to results shown by Hembree and Foa [21]. It should also be noted that the retrospective psychological health measures before the trauma captured by the clinical interview showed no differences between the therapy group and the non-therapy group. This result suggests that the obtained differences between the groups after the trauma are connected to the trauma and trauma reactions. The therapy group also scored higher on future psychological health. Although the difference was only a tendency it may suggest that the therapy group had access to a higher sense of hope. This would be in line with a discussion by Cloninger and others that hope is an important factor in health and wellbeing in the face of adversity $[29,30]$.

The therapy group scored higher on the coping style "Escape-Avoidance" than the non-therapy group. They also used the coping strategy "Accepting Responsibility" more than the non-therapy group. Both of these coping mechanisms have shown negative correlations with overall health outcomes [22]. In addition, Harrison and Kinner [31] found that victims who used more avoidant strategies also suffered more from post-trauma distress. Similar results, i.e., associations between avoidant coping strategies and impaired psychological functioning, have also been shown by Plumb et al. [18]. In sum, it appeared that the therapy group used more maladaptive coping strategies than the other group. Perhaps it is the lack of adaptive coping strategies that leads people to accept an offer of treatment. It seems reasonable, further, to assume that the therapy group would not have sought treatment on their own accord given the higher rate of avoidant coping.

Accepting responsibility coping can be linked to guiltrelated feelings of self-blame. In a study differentiating selfresponsibility from self-blame, self-blame was found to be more related to distress than self-responsibility [32]. Accepting responsibility coping may reflect the dual nature of event-related guilt discussed by Janoff-Bulman [33] among others.

A shortcoming in this study was missing data regarding the questionnaires. The problem of dropout is common in long-term clinical studies, which is one of the reasons researchers stress the need to bridge the gap between research and clinical practice [34]. On the other hand, the qualitative data from the clinical interviews in our study lent support to the validity of the obtained results. Moreover, the interrater agreement of ratings derived from the quantified data yielding severity of peritraumatic reaction (e.g. Fear) did not approach $100 \%$. Our view on this is that while not ideal the interrater reliability for these ratings was good enough. A further limitation was that the small sample sizes made it impossible to perform separate gender analyses.

In this study ASD was assessed as a part of the semistructured interview. We know that the standard way of assessment of symptoms is using a structured interview (like SCID or CIDI). However, our decision not to use this method was based on the assumption that including the ASD items in the interview would be less time consuming and might not be so taxing for the crime victims. We wanted to ask the participants about symptoms in a non-formalized way as a part of the crime victims own descriptions of reactions after the crime. While this might have had a negative effect on reliability, it might also have had a positive impact on validity. Our overall impression was that the crime victims responded with openness and sincerity. 
A conclusion is that the subjects who attended psychotherapy in this sample were indeed those who were most in need of help. A clinical implication of this is that the crime victims' own decisions regarding compliance with psychotherapy must be taken seriously, that is, even those who say they don't feel they need any help should be respected. Also, the lack of adaptive coping strategies, especially avoidant coping, seems to lend support to a more pro-active practice in regards to crime victims. It remains to be seen in a forthcoming 8-month and 2-year follow-up if the differences between these groups endure.

\section{REFERENCES}

[1] Gale JA, Coupe T. The behavioural, emotional and psychological effects of street robbery. Int Rev Victimol 2005; 12(1): 1-22.

[2] American Psychiatric Association (APA). Diagnostic and statistical manual of mental disorders (DSM-IV) $4^{\text {th }}$ ed. Washington, DC: APA 1994.

[3] Kilpatrick DG, Acierno R. Mental health needs of crime victims: epidemiology and outcomes. J Trauma Stress 2003; 16(2): 119-32.

[4] Elklit A, Brink O. Acute stress disorder in physical assault victims visiting a Danish emergency ward. Violence Vict 2003; 18(4): 46172.

[5] Bryant R. Early predictors of posttraumatic stress disorder. Biol Psychiat 2003; 53(9): 789-95.

[6] Elklit A, Brink O. Acute stress disorder as a predictor of posttraumatic stress disorder in physical assault victims. J Interpers Violence 2004; 19(6): 709-26.

[7] Carlsson EB, Dutton MA. Assessing experiences and responses of crime victims. J Trauma Stress 2003; 16(2): 133-48.

[8] O'Donnell ML, Creamer MC, Parslow R, et al. A predictive screening index for post traumatic stress disorder and depression following traumatic injury. J Consult Clin Psych 2008; 76(6): 92332.

[9] Ehring T, Ehlers A, Gluckman E. Do cognitive models help in predicting the severity of posttraumatic stress disorder, phobia, and depression after motor vehicle accidents? a prospective longitudinal study. J Consult Clin Psych 2008; 76(2): 219-30.

[10] Kamphuis JH, Emmelkamp PMG. 20 years of research into violence and trauma: Past and future developments. J Interpers Violence 2005; 20(2): 167-74.

[11] Litz BT, Gray MJ, Richard RJ, Adler AB. Early intervention for trauma: current status and future directions. Clin Psycho-Sci Pr 2002; 9(2): 112-34.

[12] Grant JD. Clinical intervention, supportive counseling and therapeutic methods: a clarification and direction for restorative treatment. Int Rev Victimol 2002; 9: 1-14.

[13] Resick PA, Galovski TE, O'Brien Uhmansiek M, Scheer CD, Clum $\mathrm{GA}$, Young-Xu Y. A randomized clinical trial to dismantle components of cognitive processing therapy for posttraumatic stress disorder in female victims of interpersonal violence. J Consult Clin Psych 2008; 76(2): 243-58.

[14] Robertson MF, Humphreys LM, Ray R. Psychological treatments for posttraumatic stress disorder: recommendations for the clinician based on a review of the literature. J Psychiatr Pract 2004; 10(2): 106-18.

[15] Bryant RA, Harvey AG. Treatment obstacles. In: Harvey RA. Allison AG, Eds. Acute stress disorder: a handbook of theory, as- sessment and treatment. Washington DC: American Psychological Association 2000.

[16] Norris FH, Kaniasty KZ, Scheer DA. Use of mental health services among victims of crime: frequency, correlates, and subsequent recovery. J Consult Clin Psych 1990; 58: 538-47.

[17] Kazdin AE. Perceived barriers to treatment participation and treatment acceptability among antisocial children and their families. J Child Fam Stud 2000; 9(2): 157-74.

[18] Plumb JC, Orsillo SM, Luterek JA. A preliminary test of the role of experimental avoidance in post-event functioning. J Behav Ther Exp Psy 2004; 35(3): 245-57.

[19] Gray MJ, Elhai JD, Frueh BC. Enhancing patient satisfaction and increasing treatment compliance: patient education as a fundamental component of PTSD treatment. Psychiatr Quart 2004; 75(4): 321-33.

[20] Clarkin JF, Levy KN. The influence of client variables in psychotherapy. In: Lambert MJ, Ed. Bergin and Garfield's Handbook of psychotherapy and behavior change (194-226). New York: John Wiley \& Sons, Inc 2004.

[21] Hembree EA, Foa EB. Interventions of trauma-related emotional disturbances in adult victims of crime. J Trauma Stress 2003; 16(2): 187-99.

[22] Penley JA, Tomaka J, Wiebe JS. The association of coping to physical and psychological health outcomes: A meta-analytic review. J Behav Med 2002; 25(6): 551-603.

[23] Green DL, Pomeroy EC. Crime victims: what is the role of social support? J Aggress Maltreat Trauma 2007; 15(2): 97-113.

[24] Mollica RF, Caspi-Yavin Y, Bollinin P, Truong T, Tor S, Lavelle J. Harvard trauma questionnaire: validating a cross-cultural instrument for measuring torture, trauma and post-traumatic stress disorder in Indochinese refugees. J Nerv Ment Dis 1992; 180(2): 111-6.

[25] Fridell M, Cesarec Z, Johansson M, Thorsen SM. Svensk normering, standardisering och validering av symtomskalan SCL-90. Statens institutionsstyrelse 2002. Rapport 4/02.

[26] Folkman S, Lazarus RS. Ways of coping questionnaire. Palo Alto, CA: Psychol Press 1998

[27] Healy CM, McKay MF. Nursing stress: the effects of coping strategies and job satisfaction in a sample of Australian nurses. $\mathbf{J}$ Adv Nurs 2000; 36: 681-8.

[28] Ahlström G, Wenneberg S. Coping with illness-related problems in persons with progressive muscular diseases: the Swedish version of the ways of coping questionnaire. Scand J Caring Sci 2002; 16(4): 368-75.

[29] Cloninger CR, Zohar AH. Personality and the perception of health and happiness. J Affect Disord 2010; 128(1-2): 24-32.

[30] Cohn MA, Fredrickson BL, Brown SL, Mikels JA, Conway AM. Happiness unpacked: positive emotions increase life satisfaction by building resilience. Emotion 2009; 9(3): 361-8.

[31] Harrison CA, Kinner SA. Correlates of psychological distress following armed robbery. J Trauma Stress 1998; 11(4): 787-98.

[32] Delahanty DL, Herberman HB, Craig KJ, et al. Acute and chronic distress and posttraumatic stress disorder as a function of responsibility for serious motor vehicle accidents. J Consult Clin Psychol 1997; 65(4): 560-7.

[33] Janoff-Bulman R. Characteriological versus behavioral self-blame: Inquiries into depression and rape. J Pers Soc Psychol 1979; 37(10), 1798-809.

[34] Kazdin AE. Research design in clinical psychology, $4^{\text {th }}$ ed. Boston: Allyn \& Bacon 2003. 